\title{
Centralising and optimising decentralised stroke care systems: a simulation study on short-term costs and effects
}

\author{
Maarten M. H. Lahr ${ }^{1 *}$, Durk-Jouke van der Zee ${ }^{2}$, Gert-Jan Luijckx ${ }^{3}$ Patrick C. A. J. Vroomen ${ }^{3}$ and Erik Buskens ${ }^{1}$
}

\begin{abstract}
Background: Centralisation of thrombolysis may offer substantial benefits. The aim of this study was to assess short term costs and effects of centralisation of thrombolysis and optimised care in a decentralised system.

Methods: Using simulation modelling, three scenarios to improve decentralised settings in the North of Netherlands were compared from the perspective of the policy maker and compared to current decentralised care: (1) improving stroke care at nine separate hospitals, (2) centralising and improving thrombolysis treatment to four, and (3) two hospitals. Outcomes were annual mean and incremental costs per patient up to the treatment with thrombolysis, incremental cost-effectiveness ratio (iCER) per 1\% increase in thrombolysis rate, and the proportion treated with thrombolysis.
\end{abstract}

Results: Compared to current decentralised care, improving stroke care at individual community hospitals led to mean annual costs per patient of $\$$ US $1,834(95 \% \mathrm{Cl}, 1,823-1,843)$ whereas centralising to four and two hospitals led to \$US $1,462(95 \% \mathrm{Cl}, 1,451-1,473)$ and $\$ U S 1,317(95 \% \mathrm{Cl}, 1,306-1,328)$, respectively $(P<0.001)$. The iCER of improving community hospitals was \$US 113 (95\% Cl, 91-150) and \$US 71 (95\% Cl, 59-94), \$US 56 (95\% Cl, 44-74) when centralising to four and two hospitals, respectively. Thrombolysis rates decreased from 22.4 to $21.8 \%$ and $21.2 \%$ $(P=0.120$ and $P=0.001)$ in case of increasing centralisation.

Conclusions: Centralising thrombolysis substantially lowers mean annual costs per patient compared to raising stroke care at community hospitals simultaneously. Small, but negative effects on thrombolysis rates may be expected.

Keywords: Stroke, Simulation models, Organisational model, Costs, Thrombolysis

\section{Background}

Treatment with thrombolysis or tissue plasminogen activator (tPA) in stroke centres as part of a centralised organisational model is associated with better patient outcomes and higher thrombolysis rates compared to community hospitals in a decentralised model [1]. In addition to better patient outcomes, centralisation of thrombolysis may lead to substantial cost-savings $[2,3]$. Compared to stroke care at community hospitals, admission to a stroke centre was associated with an incremental cost-effectiveness ratio of US\$24,000 per

\footnotetext{
* Correspondence: m.m.h.lahr@umcg.nl

${ }^{1}$ Health Technology Assessment, Department of Epidemiology, University of Groningen, University Medical Centre Groningen, Hanzeplein 1, P.O. Box 30001, 9700 RB Groningen, The Netherlands

Full list of author information is available at the end of the article
}

quality-adjusted life year gained [4]. For every 5\% absolute increase in thrombolysis rates, an additional 30,000 patients annually may be treated within a US region containing 109 designated stroke centres. Within the Netherlands, a Breakthrough Series-based implementation program increased thrombolysis use and saved short- and long-term healthcare costs due to lower hospital admission and residential costs, and increasing stroke care efficiency [5]. The short-term costs and resource implications associated with advancing community hospital stroke care to the standards of a stroke centre however remain unclear, hampering broad implementation of thrombolysis.

Because distances to hospitals offering thrombolysis in the Netherlands are relatively short [6], decentralised 
stroke systems may be improved in two ways: (1) raising stroke care to the standards of a stroke centre in all individual community hospitals simultaneously, and (2) centralising and simultaneously improving thrombolysis treatment thereby reducing the number of community hospitals offering thrombolysis. Prior to large-scale implementation, the clinical, financial and personnel implications of both scenarios should be assessed. In addition, because the efficacy of thrombolysis is strongly time-dependent (i.e., the sooner the better) [7], we considered how time to treatment and travel time to the hospital would influence patient outcomes.

Using a simulation model, the aims of this study were: (1) to estimate the short-term costs, up to treatment with IPA, and the incremental cost-effectiveness ratio associated with raising stroke care at all community hospitals simultaneously compared to centralisation of thrombolysis treatment and (2) to estimate the effects of centralisation on the average days of extra healthy life, proportion of patients treated with thrombolysis, total process time, and travel time.

\section{Methods}

The present study was based on a previously published 6 -month prospective study on a centralised ( $n=280$ of which 124 thrombolysis candidates) and decentralised ( $n=801$ of which 227 thrombolysis candidates) organisational model of acute stroke care within a Dutch region [1]. A summary on patient recruitment, baseline patient characteristics, population densities, and access to healthcare services is provided elsewhere [1]. Variables were obtained from patients admitted to hospitals during a 6 month prospective study from February to July 2010. Data collection focused on time delays along both the pre- and intrahospital acute stroke pathway, and on diagnostic accuracy such as choice for first responder and ambulance transportation.

\section{Organisational models of acute stroke care}

In the North of the Netherlands, a centralised and decentralised organisational model co-exist. The decentralised model comprises nine community hospitals in which tPA treatment is provided to patients in their catchment area. Community hospitals included in this study were medium to large hospitals with 100 to 400 stroke patients admitted per year. University Medical Centre Groningen (UMCG) acting as stroke centre served as an example of centralised stroke care. Acute stroke pathway set-up was identical for both organisational models. The stroke centre has 24-h, 7-day acute stroke care coverage, including immediate access to neuroimaging (CT, Computed Tomography scan) and examination at the Emergency Department (ED). Within all hospitals offering thrombolysis, treatment was given within a stroke unit according to identical protocols for tPA treatment (adjusted ECASS III) [8]. Distances and access to healthcare services such as General Practitioners (GP) offices and Emergency Medical Services (EMS) are typically short. EMS protocols were available for GP offices, ambulance dispatch centres and ambulance personnel $[9,10]$. The population density and distribution were roughly similar for the centralised- and decentralised organisational models, i.e., 250 and 190 inhabitants per $\mathrm{km}^{2}$, respectively. Within the region a well-developed and thin branched road network exists with minimal traffic congestion.

\section{Simulation model}

A discrete-event simulation model was designed using Plant Simulation software [11] to replicate current practice of community hospitals based on parameter estimations obtained in the prospective study [1]. A previously developed simulation model was used and extended to represent input data from the decentralised model [12]. Acute stroke pathway set-up is depicted in Fig. 1. Time

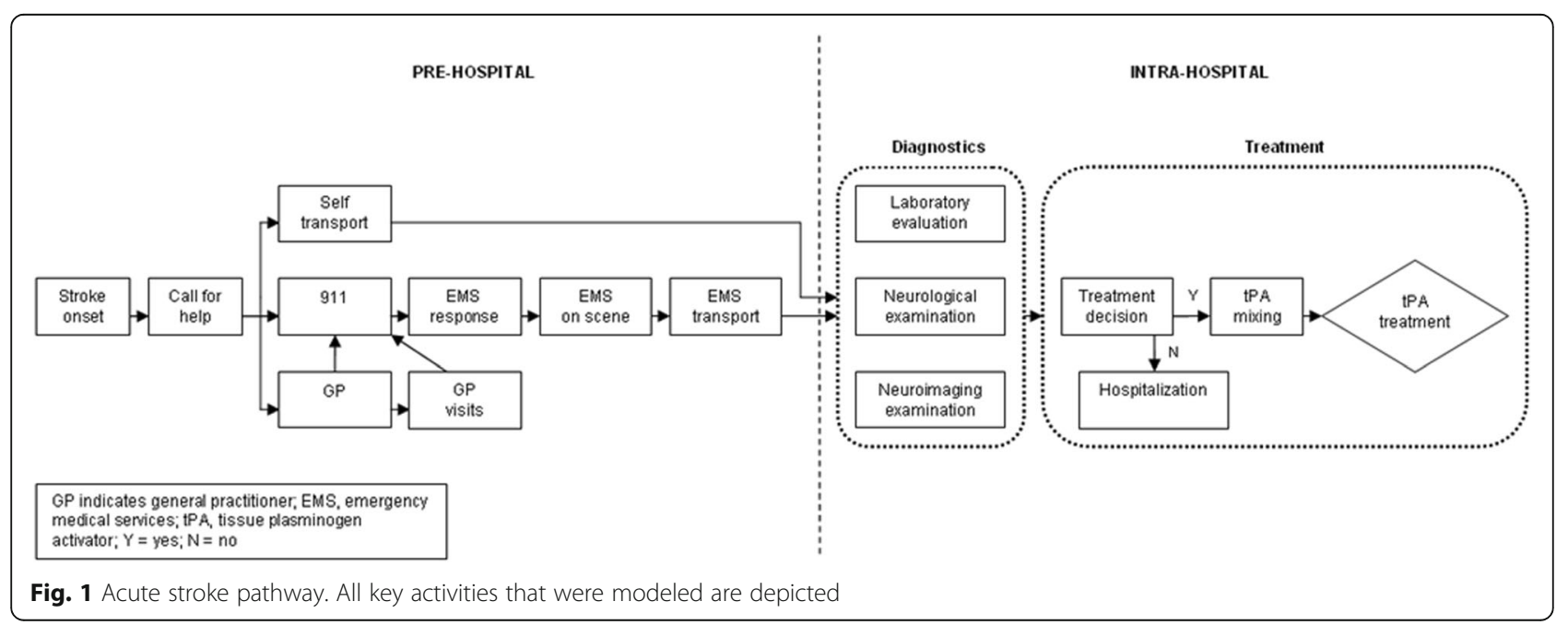


delays and diagnostic processes were modeled along the pre-hospital and in-hospital stroke pathway using statistical distributions as observed (Table 1). Statistical distributions were determined (fitted) using ExpertFit $[13,14]$. Costs associated with resource use were accounted for in the model. Compared to current decentralised care, three scenarios for improving decentralised stroke care were considered from the perspective of the policy maker: (1) simultaneously improving stroke care at all community hospitals, (2) centralisation and improvement of acute stroke care in four, and (3) in two community hospitals, thereby reducing the number of community hospitals offering thrombolysis (Fig. 2). The community hospitals hypothetically acting as stroke centres were chosen based on their geographical location within a region. The UMCG also participated in these scenarios as stroke centre. For the last two scenarios the effect of centralisation on travel time to the treating hospital was assessed. In all scenarios the level of stroke care at hospitals was assumed to rise to the performance of the centralised model; i.e., $22 \%$ of all ischaemic stroke patients would be administered thrombolysis [1]. Centralisation only affects those patients for whom delay from stroke onset to the moment of transportation is within the window of opportunity for tPA treatment, i.e., within $4.5 \mathrm{~h}$. All patients facing a delay of more than $4.5 \mathrm{~h}$ were sent to the nearest community hospital.

Improvements associated with centralisation of thrombolysis treatment were implemented in the simulation model. Pre-hospital factors modeled included: lapse between stroke onset and call for help, GP consultation, EMS use, and high priority ambulance transportation (i.e., arrival within $15 \mathrm{~min}$ after alert). Data collected in the prospective study included the travel time from the exact geographical location of the patient to the hospital providing thrombolysis for all patients transported by EMS. In-hospital factors included time from hospital arrival to neurological examination, neuroimaging (CT scan), laboratory examination, and treatment with thrombolysis. In the model 10,000 patients progressed along the stroke pathway. Additional file 1: Tables S1 and S2 describe model parameters for the improved decentralised model ( 9 hospitals), and effects of centralisation on choice of distributions representing patient transport from the incident scene to a designated hospital (4, 2 hospitals). Further details on simulation methodology, model validation, and model data are provided in Additional file 1: Methods.

\section{Cost calculation}

The costs associated with resource use along the stroke pathway for fixed and variable costs are presented in Table 2. Short-term costs up to treatment with thrombolysis were considered, because these were available.
Data was collected on resource use at the level of all individual patients in both the pre-hospital and intrahospital phase of the stroke pathway. Unit costs were entered into the simulation model and contributed to overall resource use.

Mean and incremental annual costs per patient were estimated for all scenarios including fixed and variable costs. Fixed costs were considered constant whereas variable costs fluctuated directly with patient volumes. Fixed costs included recurring annual public education campaigns and staff education. The purchase of a new CT scanner located in the ED was considered a one-time investment. Yearly depreciation costs for a new CT scanner were conservatively estimated at $10 \%$ of the initial investment [15]. Variable costs estimated included GP consultation either by telephone or visit, EMS utilisation, staff deployment associated with activation of the acute stroke team including a stroke neurologist, resident neurology, stroke nurse and treatment with thrombolysis (alteplase). All patients irrespective of eligibility for thrombolysis underwent neurological examination, CT scanning, and laboratory examination, either in the ED for those arriving within the $4.5 \mathrm{~h}$ time window or in the outpatient clinic. No additional staff deployment (emergency physicians, neurologists, radiologists or nurses) was anticipated in case of centralisation of thrombolysis, based on expert judgment. Costs per ambulance ride include tariffs for emergency transport, EMS dispatch, and costs per driven kilometer. Costs for deployment of medical personnel per hour included a 39\% bonus for social gratuity, holiday pay, and other. To allow estimating annual costs and patient throughput the 6-month study period was extrapolated to 1 year assuming similar resource utilisation serving 1602 patients in the decentral model. The costs in euro's were adjusted to the current euro-dollar exchange index of 1.12 \$US per 1 Euro [16]. Mean resource consumption per patient is presented in Additional file 1: Table S3.

\section{Travel time and distance}

Travel time and distance in case of centralisation of thrombolysis treatment was assessed by hypothetically transporting patients from the emergency site to the nearest hospital offering thrombolysis. Only those patients transported by EMS were included in this analysis, because of availability of data on exact geographical locations for this group. In the scenario of centralisation of thrombolysis, travel time and distance were calculated with the use of a Web based route planner (http://rou te.anwb.nl/routeplanner) as the product of estimated distances and projected travel speeds, consistent with strategies used in previous studies $[17,18]$. The values obtained by the Web-based route planner were corrected to represent real-world data, as the route planner 
Table 1 Distributions specifying activity durations and diagnostic characteristics for the current decentralised model Activity duration (minutes)

Model parameter Distribution: type Parameters

Time from stroke onset to call for help Continuous empirical

Route 1

Route 2

Route 3

Delay first responder

911 call

GP consult by telephone

GP consult by visit

EMS

Response time

A1

A2

B

\section{Uniform \\ Uniform \\ Triangle}

Continuous empirical

Gamma

Beta
Left bound

0

5

10

15

30

45

60

120

180

240

480

Right bound

5

\section{0}

15

30

45

60

120

180

240

480

2880

5

10

15

2880

60

120

180

240

480

2880

286

39

21

15

35

33

14

40

16

10

9

230

1

1

1

15

9

17

3

4

2
Frequency

Min (1.00), Max (2.00)

$\operatorname{Min}(2.00), \operatorname{Max}(5.00)$

Mode (40.00), Min (10.00), Max (30.00)

Left bound

Right bound

Frequency

0

5

10

15

20

25

30

35

Alpha (3.36), Beta (4.22)

Alpha 1 (0.69), Alpha 2 (0.53), a (8.92), b (59.33)
53

145

85

23

2

1

0

2 
Table 1 Distributions specifying activity durations and diagnostic characteristics for the current decentralised model (Continued) Time spent on scene

A1

A2
B
Transport time
A1
A2
B
Time to neurological consultation

Time to neuroimaging (CT) examination
Continuous empirical

Left bound
0
5
10
15
20
25
30
35
40
45

Right bound

Frequency

Lognormal

Lognormal

Beta

Gamma

Beta

Continuous empirical

a

Mean (15.24), St. dev. (7.67)

Mean (15.12), St. dev. (8.14)

Alpha1 (1.69), Alpha2 (4.16), a (39.66), b (0.62)

Alpha (5.53), Beta (2.51)

Alpha 1 (1.07), Alpha 2 (1.41), a (0.02), b (31.61)

Left bound

Right bound

Frequency

$$
0
$$

0

1

2

5

10

15

30

Continuous empirical
3

45

106

87

39

13

8

3

4

2

\section{Left bound}

$$
0
$$

5

10

15

20

25

30

35

40

45

50

\section{0}

1

2

\section{5}

10

15

30

72

Right bound

\section{5}

10

15

20

20

25

30

35

40


Table 1 Distributions specifying activity durations and diagnostic characteristics for the current decentralised model (Continued)

\begin{tabular}{|c|c|c|c|c|}
\hline \multirow[t]{12}{*}{ Time to laboratory examination } & Continuous empirical & Left bound & Right bound & Frequency \\
\hline & & 0 & 0 & 61 \\
\hline & & 0 & 10 & 5 \\
\hline & & 10 & 15 & 8 \\
\hline & & 15 & 20 & 14 \\
\hline & & 20 & 25 & 18 \\
\hline & & 25 & 30 & 16 \\
\hline & & 30 & 35 & 14 \\
\hline & & 35 & 40 & 20 \\
\hline & & 40 & 45 & 18 \\
\hline & & 45 & 50 & 12 \\
\hline & & 50 & 80 & 16 \\
\hline Treatment decision & Triangle & \multicolumn{3}{|c|}{ Mode (10), Min (5), Max (20) } \\
\hline tPA mixing & Constant & 5 & & \\
\hline \multicolumn{5}{|l|}{ Diagnostics } \\
\hline Choice of route & Discrete empirical & Value & & Frequency \\
\hline 1. EMS transport & & 1 & & 462 \\
\hline 2. In-hospital & & 2 & & 18 \\
\hline 3. Self-transport & & 3 & & 321 \\
\hline Choice first responder & Discrete empirical & Value & & Frequency \\
\hline 1. 911 call & & 1 & & 184 \\
\hline 2. GP consult by phone & & 2 & & 56 \\
\hline 3. GP consult by visit & & 3 & & 126 \\
\hline EMS transport, level of urgency & Discrete empirical & Value & & Frequency \\
\hline \multicolumn{5}{|l|}{911 call } \\
\hline 1. A1 & & 1 & & 92 \\
\hline 2. $A 2$ & & 2 & & 7 \\
\hline 3. $\mathrm{B}$ & & 3 & & 1 \\
\hline \multicolumn{5}{|l|}{ GP consult by telephone } \\
\hline 1. A1 & & 1 & & 60 \\
\hline 2. $A 2$ & & 2 & & 39 \\
\hline 3. $B$ & & 3 & & 1 \\
\hline \multicolumn{5}{|l|}{ GP consult by visit } \\
\hline 1. A1 & & 1 & & 47 \\
\hline 2. $A 2$ & & 2 & & 42 \\
\hline 3. $B$ & & 3 & & 11 \\
\hline
\end{tabular}

Route 1, 2, and 3 indicate patients transported by emergency medical services, those suffering a stroke in the hospital, and patients arriving by self transport, respectively; GP General practitioner, EMS Emergency medical services; A1, A2, B indicate normative values for ambulance arrival within 15, 30, and >30 min from the 911 call until arrival at the location of the patients, respectively; CT, computed tomography; tPA, tissue plasminogen activator. Neurological examination, neuroimaging, and laboratory examination are considered parallel activities

does not account for faster driving speed achieved by ambulance transportation.

\section{Outcomes measures}

The primary end-points were mean and incremental costs per patient associated with all scenarios. Incremental cost-effectiveness ratios (iCERs) concerning the changes in effects (chance of being thrombolysed) and costs associated with improvement and centralisation scenarios vs. the current decentralised model were calculated. Secondary end-points, using the simulation model, included Onset to Treatment Time (OTT), estimations of extra healthy life days calculated using OTT estimates obtained from the simulation model and 
a

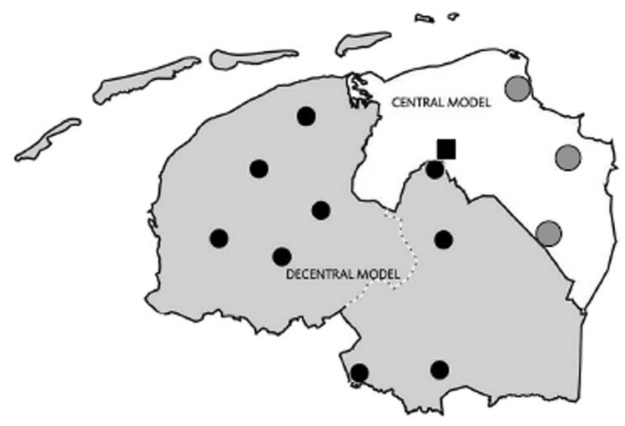

b
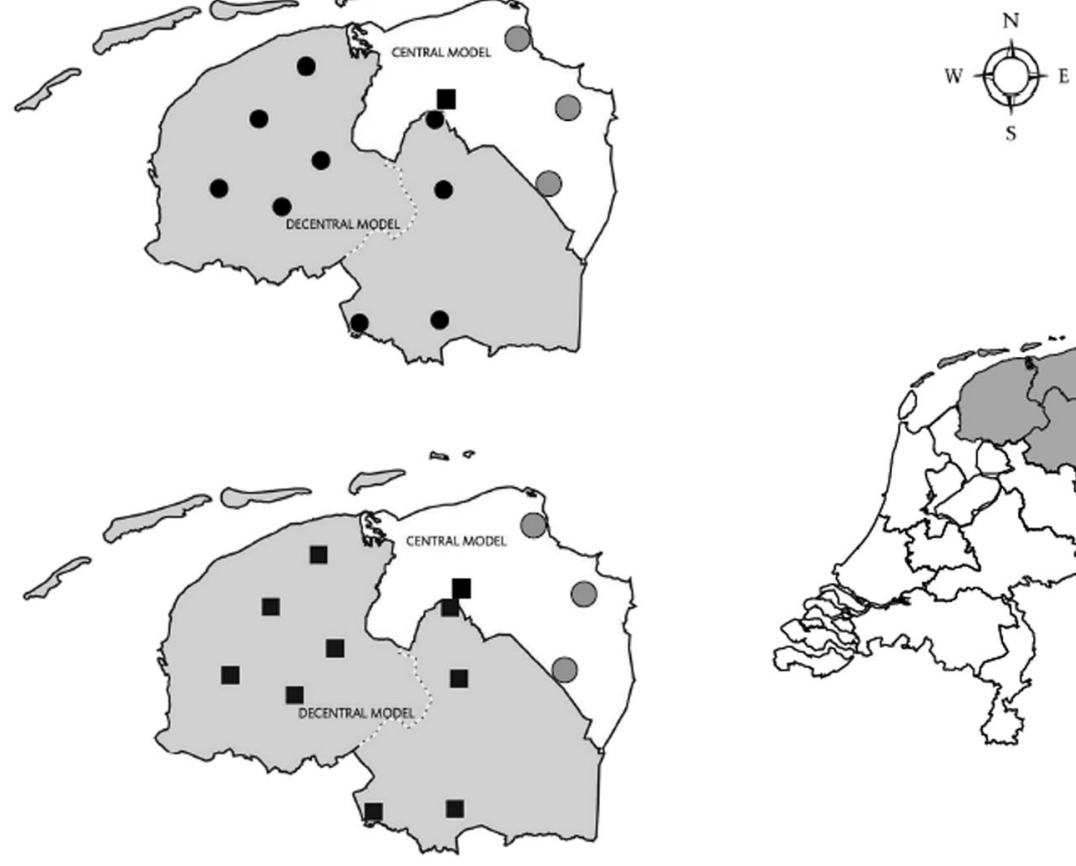

C
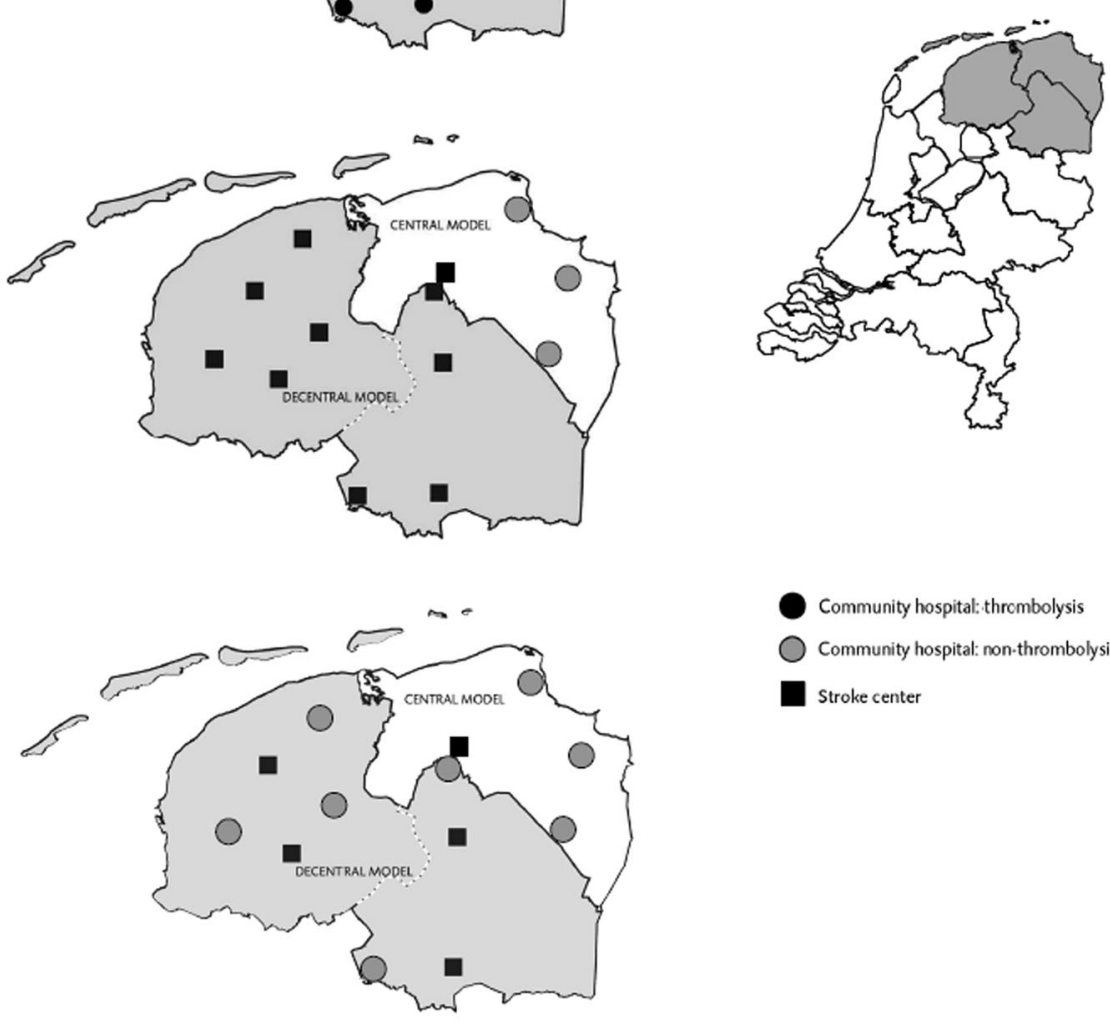

d
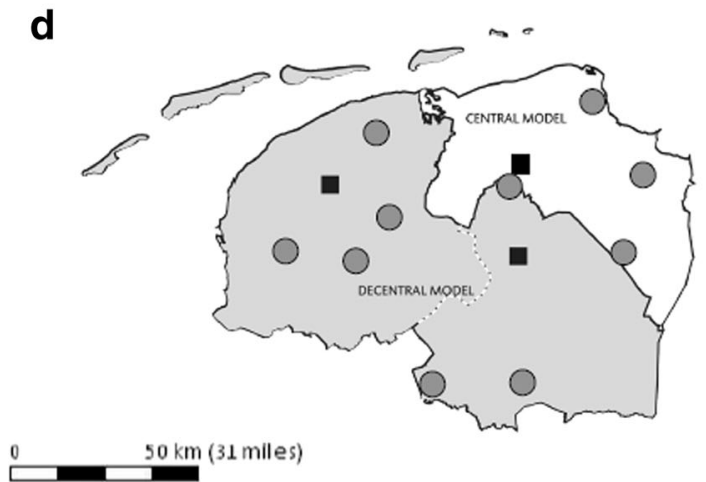

Community hospital: thrombolysis

Community hospital: non-thrombolysis

Stroke center

Fig. 2 Acute stroke care set-up scenario's. Current organisational models for acute stroke care in the Northern part of the Netherlands. Within the centralised model thrombolysis is only given in the University Medical Centre Groningen acting as a stroke centre. Arrangements were made with surrounding community hospitals (grey circles) to transport suspected acute stroke patients directly to the stroke centre. The decentralised model consists of nine community hospital all providing thrombolysis within their catchment area (a). Improving acute stroke care at all community hospital in the decentralised model to the level of a stroke centre (b). Centralisation of the decentral model from nine to four community hospitals (c). Centralisation of the decentral model from nine to two hospitals (d) 
Table 2 Unit costs for resource utilization

\begin{tabular}{|c|c|c|}
\hline Resource & Unit costs (USD) & Source \\
\hline \multicolumn{3}{|l|}{ Variable costs } \\
\hline General practitioner & & $(1)$ \\
\hline Telephonic consultation & $\$ 19.04$ & \\
\hline Visit by general practitioner & $\$ 56.00$ & \\
\hline Emergency medical services transport & & $(2)$ \\
\hline Emergency transport & $\$ 882.00$ & \\
\hline Dispatch & $\$ 71.00$ & \\
\hline Per driven kilometer & $\$ 5.00$ & \\
\hline Medical personnel ER visit & & $(1)$ \\
\hline Medical specialist (15 min) & $\$ 44.38$ & \\
\hline Resident (1 h) & $\$ 36.48$ & \\
\hline Nurse (1 h) & $\$ 35.04$ & \\
\hline Outpatient clinic visit & $\$ 89.60$ & $(1)$ \\
\hline Computed tomography scan & $\$ 144.48$ & (3) \\
\hline Central laboratory (per test) & $\$ 27.10$ & $(4)$ \\
\hline Alteplase & $\$ 532.46$ & (5) \\
\hline \multicolumn{3}{|l|}{ Fixed costs } \\
\hline Public education campaigns (range) & $\$ 3,750(\$ 2,500-\$ 5,000)$ & (6) \\
\hline Staff education (range) & $\$ 7,500(\$ 5,000-\$ 10,000)$ & $(6)$ \\
\hline Computed tomography scan & & (7) \\
\hline Purchase computed tomography scan & $\$ 1,310,000$ & \\
\hline
\end{tabular}

recently published results on the effects of reducing OTT on extra healthy life [19], the effect of additional travel time in case of centralisation on thrombolysis rates, those thrombolysed within $1.5 \mathrm{~h}$, and the OTT. The OTT is of interest because the efficacy of thrombolysis is time-dependent, i.e., sooner translates into better functional outcome and long-term health benefits (extra healthy life years), in which each minute reduction in OTT results in an average 1.8 days of extra healthy life [20-22]. In addition again based on the OTT we estimated the functional outcomes in terms of the modified Rankin scale. The modified Rankin Scale score is a commonly used scale to measure disability and independence in stroke victims [23]. The scale consists of six grades, from 0 to 5 , with 0 corresponding to no symptoms and 5 corresponding to severe disability. Furthermore, we performed a sensitivity analysis to determine how a relative $25 \%$ increase or decrease in travel time would influence results in terms of thrombolysis rates, those thrombolysed within $1.5 \mathrm{~h}$, and the OTT.

\section{Analysis}

Costs were assessed separately and presented as means with their corresponding 95\% CIs for all scenarios. iCER confidence intervals were estimated using a nonparametric bootstrap method [24], thereby building on simulation output data available for each of the scenarios. Travel times and distances were presented as medians with their corresponding 95\% CIs. MannWhitney U and Fisher's exact tests were performed for continuous and categorical variables. SPSS 20.0 for Windows software package (Chicago, IL) was used. A $p$-value $<0.05$ was considered statistically significant.

\section{Informed consent}

Informed consent was obtained from all subjects participating in the prospective study [1] and extended for current use. The study was approved by the institutional review board of UMCG.

\section{Results}

\section{Primary outcomes}

Mean annual costs per patient for current decentralised care are \$US 922 (95\% CI, 911-934). Compared to current decentralised care, improving stroke care at community hospitals separately led to mean annual costs per patient of \$US 1,834 (95\% CI, 1,823-1,843). Centralising thrombolysis led to a mean annual costs of \$US 1,462 (95\% CI, 1,451-1,473) when centralising to four, and \$US 1,317 (95\% CI, 1,306-1,328) when centralising to two hospitals $(P<0.001)$, respectively. The iCER for improving stroke care at all nine community hospitals was \$US 113 (95\% CI, 91-150) per \% increase in

Table 3 Results simulation experiments

\begin{tabular}{|c|c|c|c|c|c|c|c|}
\hline Scenario & tPA rate $(95 \% \mathrm{Cl})$ & $\begin{array}{l}\text { tPA } \\
0-90 \text { min }\end{array}$ & $\begin{array}{l}\text { tPA } \\
90-180 \mathrm{~min}\end{array}$ & $\begin{array}{l}\text { tPA } \\
180-270 \mathrm{~min}\end{array}$ & $\begin{array}{l}\mathrm{mRS} \\
0-1^{\mathrm{a}}\end{array}$ & $\begin{array}{l}\text { OTT minutes } \\
(95 \% \mathrm{Cl})\end{array}$ & $\begin{array}{l}\text { Extra healthy life days } \\
(95 \% \text { prediction interval) }\end{array}$ \\
\hline 0. Current decentralised stroke care & $14.4 \%(13.7 \%-15.1 \%)$ & $14.3 \%$ & $70.5 \%$ & $15.2 \%$ & $14.7 \%$ & $134(131-136)$ & \\
\hline $\begin{array}{l}\text { 1. Optimising all } 9 \text { Community } \\
\text { hospitals }\end{array}$ & $22.4 \%(21.6 \%-23.2 \%)$ & $27.5 \%$ & $62.0 \%$ & $10.5 \%$ & $26.6 \%$ & $119(117-127)$ & $27.0(13.5-40.5)$ \\
\hline 2. Centralisation (4 stroke centers) & $21.8 \%(21.0 \%-22.7 \%)$ & $25.1 \%$ & $63.2 \%$ & $11.7 \%$ & $25.3 \%$ & $122(120-124)$ & $21.6(10.8-32.4)$ \\
\hline 3. Centralisation (2 stroke centres) & $21.2 \%(20.4 \%-22.0 \%)$ & $21.6 \%$ & $66.6 \%$ & $11.9 \%$ & $23.8 \%$ & $125(123-127)$ & $16.2(8.1-24.3)$ \\
\hline
\end{tabular}

tPA indicates tissue plasminogen activator; $\mathrm{Cl}$, confidence interval; $\mathrm{mRS}$, modified rankin scale; OTT, onset treatment time

${ }^{a}$ Indicates the proportion of patients with excellent functional outcome (mRS 0-1) ascribed with thrombolysis treatment [12]

${ }^{b}$ Indicates the number of additional days in healthy life per minute reduction in OTT [11] 
thrombolysis rate compared to \$US 71 (95\% CI, 5994) and \$US 56 (95\% CI, 44-72) when centralising to four and two hospitals.

\section{Secondary outcomes}

Table 3 describes the results of the three scenarios performed with the simulation model. Compared to current decentralised care, optimising stroke care at all nine community hospitals resulted in an average 27.0 days of extra of healthy life (95\% prediction interval 13.5-40.5), compared to 21.6 days $(95 \%$ prediction interval $10.8-32.4$ ) and 16.2 days (95\% prediction interval 8.1-24.3) when centralising to four and two stroke centres, respectively.

Baseline travel times and distances in case of centralisation are presented as medians with their 95\% CIs in Table 4. Overall, centralisation of thrombolysis treatment resulted in travel times of 16.0 (95\% CI, 3.0-31.9) and $21.2 \mathrm{~min}(95 \% \mathrm{CI}, 4.0-37.7)$ in case of four- and two community hospitals, respectively, compared to $12.0 \mathrm{~min}$ (95\% CI, 2.0-30.0) in the baseline model $(P<0.001)$. Travel distance increased to $19.7 \mathrm{~km}(95 \% \mathrm{CI}, 1.1-42.5)$ and $26.4 \mathrm{~km}$ (95\% CI, 1.4-54.5), respectively, compared to $11.6 \mathrm{~km}, 95 \% \mathrm{CI}, 0.9-31.0)$ in the baseline model $(P<0.001)$.

\section{Sensitivity analysis}

In case of centralisation of thrombolysis to four hospitals, a decrease of $25 \%$ in travel time increased the proportion of patients treated with thrombolysis with $0.4 \%$ (from 21.8 to $22.2 \%, P=0.544)$, those thrombolysed within $1.5 \mathrm{~h}$ increased from 25.1 to $28.2 \%(P=0.021)$, and OTT decreased from 121.9 to $119.1 \mathrm{~min}(P=0.048)$. An increase of $25 \%$ in travel time decreased the proportion of patients treated with thrombolysis by $0.4 \%$ (from 21.8 to $21.4 \%, P=0.477$ ), those thrombolysed within $1.5 \mathrm{~h}$ decreased from 25.1 to
22.4\% $(P=0.038)$, and the OTT increased from 121.9 to $124.7 \min (P=0.057)$.

In case of centralisation of thrombolysis to two hospitals, a decrease of $25 \%$ in travel time increased the proportion of patients treated with thrombolysis with $0.5 \%$ (from 21.2 to $21.7 \%, P=0.344$ ), those thrombolysed within $1.5 \mathrm{~h}$ increased from 21.6 to $25.1 \%(P=0.001)$, and OTT decreased from 124.5 to $120.9 \mathrm{~min}(P=0.001)$. An increase of $25 \%$ in travel time decreased the proportion of patients treated with thrombolysis by $0.6 \%$ (from 21.2 to $20.6 \%, P=0.311$ ), those thrombolysed within $1.5 \mathrm{~h}$ decreased from 21.6 to $19.4 \%(P=0.088)$, and OTT increased from 124.5 to 127.7 $(P=0.027)$.

\section{Discussion}

This study demonstrated that centralisation of thrombolysis may lead to substantial annual cost-savings per patient compared to a scenario in which stroke care would be improved at all separate community hospitals. Mean costs were lowest when reducing the number of community hospitals offering thrombolysis from nine to two facilities.

The iCER analyses indicated that marginal gains of improving additional community hospitals comes at increasing costs. Furthermore, extended dominance was observed for the less centralised stroke care scenario. Estimating the costs associated with a $1 \%$ improvement in tPA treatment rate, and the number needed to treat of 1 in 7 patients on average keeps out nursing home (average annual costs well over €50,000) [25], it becomes clear that the investments required would be quickly regained. We assumed comparable effects of expediting thrombolysis treatment on extra healthy life years, i.e., 1 min reduction in total process time translates into one additional day of healthy life for each patient treated with thrombolysis. This was based on similarities between our population [1] and the one described in the

Table 4 Travel times and distances for the baseline case and centralisation

\begin{tabular}{llll}
\hline All patients & Optimising all 9 community hospitals & Centralisation (4 stroke centres) & Centralisation (2 stroke centres) \\
\hline Estimated travel time & & 446 & 446 \\
N & 446 & $16(10-22) \dagger$ & $21(15-26) \dagger$ \\
Median (95\% Cl) & $12(2-30)$ & $47(10)$ & $32(7)$ \\
$<5$ min (\%) & $86(19)$ & $333(75)$ & $278(62)$ \\
$5-25$ min (\%) & $337(76)$ & $66(15)$ & $136(31)$ \\
$>25$ min (\%) & $23(5)$ & & $26(1-55)+$ \\
Estimated travel distance & & $20(1-43) \dagger$ & $69(16)$ \\
Median (95\% Cl) & $12(1-31)$ & $91(20)$ & $139(31)$ \\
$<5 \mathrm{~km}(\%)$ & $140(31)$ & $221(50)$ & $238(53)$ \\
$5-25 \mathrm{~km} \mathrm{( \% )}$ & $262(59)$ & $134(30)$ &
\end{tabular}

$\mathrm{Cl}$ indicates confidence interval 
literature [19] in terms of demographics and outcome distributions (modified Rankin Scale scores). When compared to a hypothetical optimised decentral system centralisation of thrombolysis was projected to lead to small, but statistically significant negative effects on the proportion patients treated with thrombolysis, OTT, and fewer additional healthy life years. Whether the better secondary outcomes attained with the optimised decentral system would outweigh the greater costs in terms of long-term health and outcomes remains unclear and is subject of future study. As estimating iCER in terms of cost per year free of stroke symptoms would rely on additional assumptions and thus introducing further uncertainty we refrained from estimating this outcome. Long-term effects were not taken into consideration as the long-term consequences slight increases OTT are difficult to interpret. In any case, this suggests that centralising thrombolysis treatment should be accompanied by initiatives to reduce time delays in other parts of the chain of care; for example by reducing the door-needletime. Importantly, thrombolysis rates in a centralised system would clearly surpass those of current decentralised care. Because of inequalities in geographic and resource availability between regions and facilities, our analysis provides broadly applicable estimates yet might lack generalisability. However, to account for the potential effects of, among others, population density, regional geography, and traffic congestion, and to generalise the findings presented in this study to other regions, a sensitivity analysis on transport times was performed. The sensitivity analyses demonstrated that moderate changes in travel times did not substantially alter results, suggesting robustness of our findings. In addition, by manipulating input model parameters, i.e., performing scenario and sensitivity analyses, for example travel distances, less densely populated areas could also be represented thus assisting in optimising the chain of care in other settings as well.

The results of this study corroborate the relevance of applying organisational models for the configuration of acute stroke care for a region, instead of local improvements in an individual chain of care. Stroke centre designation will impact on hospital services in several ways. First, available resources may be re-distributed if the hospital needs to purchase expensive equipment, hire more staff, or expand bed capacity. The question whether additional staff is needed to match an increase in patient volumes when thrombolysis treatment is centralised remains speculative, and further evidence is urgently needed. Assuming an annual gain in thrombolysis candidates of $16 \%$ as a result of centralisation, staff members may be deployed an additional 256 times annually, from 449 (28\% of 1602 stroke patients) to 705 (44\% of 1602 patients). In case the appropriate equipment and staff are already available, changes may only be necessary in terms of the time of day staff will be on call, i.e., more hours into a stroke team. This would imply that the capacity of stroke centres does not require expanding despite an increase in patient load. Whether or not this is realistic is subject of further study. Improving coordination of care through stroke centre designation reduces duplication of efforts and redundant diagnostic testing. In particular, less personnel, work hours, and materials are needed. Therefore limited hospital budgets only have to be spent once in a centralised setting instead of raising stroke care at all community hospitals separately. Furthermore, being a stroke centre likely will increase the use of other hospital departments and services, i.e., radiology and laboratory services, which may result in increased revenues [26].

Unavoidably centralisation leads to longer travel times from the emergency site to the hospital offering thrombolysis. Yet, as demonstrated in a previously published study this can be compensated by shorter intra-hospital processes (door-to-needle time) of $35 \mathrm{~min}$ compared to $47 \mathrm{~min}$ in a decentralised model [1]. In addition, previous research showed that the door-to-needle time may be further shortened to $20 \mathrm{~min}$ in optimised settings [27, 28]. We assumed that centralising stroke care may lead to a doubling of emergency rides by EMS; this would not require hiring additional EMS personnel or purchasing additional vehicles. However this too remains a topic for further study.

Our study has limitations. First, as a short-term time horizon, i.e., only the costs up to treatment with thrombolysis were considered, effects of e.g., postponed therapy such as long-term sequelae of ischaemic strokes could not be taken into account. Future studies should try to include long-term data in their analyses, or use historical data from review articles. Secondly, costs associated with thrombolysis such as antithrombotic and lipid lowering medications were not part of the assessment and could therefore not be controlled for. Future studies should try to collect these variables prospectively and include them in the costs analyses. Third, we mostly used tariffs rather than societal costs for our analyses. Also, the effects of improved patient outcomes on the frequency and intensity of informal (family) care should be assessed. An additional concern is the potential for traffic congestion which might influence estimated travel times in our study. However, all patients included in this study had access to 911-systems, and previous research indicated that traffic patterns only minimally affects ambulance travel times [29]. Finally, we did not consider the possibility of misdirecting patients to decentralised hospitals based on incorrect EMS assessments. However, both recent research [30], and our own prospective data on the studied region indicate how suchlike misinterpretations involve only $1-2 \%$ of the patient population. 


\section{Conclusions}

Centralisation of thrombolysis leads to substantially lower annual costs per patient compared to raising the level of stroke care at community hospitals simultaneously. Small, but negative effects on average days of healthy life, thrombolysis rates, and OTT may be expected compared to optimised decentral care.

\section{Additional file}

Additional file 1: Table S1. Distributions specifying activity durations and diagnostic characteristics for the optimised decentralised model in case of centralisation. Table S2. Model parameter distributions for emergency medical services transport to hospital in case of centralisation. Table S3. Mean resource consumption per patient for the different scenarios. (DOCX $47 \mathrm{~kb}$ )

\section{Abbreviations}

CT: Computed Tomography; ED: Emergency Department; EMS: Emergency Medical Services; GP: General Practitioner; iCER: Incremental Cost Effectiveness Ratio; OTT: Onset Treatment Time; tPA: Tissue plasminogen activator; UMCG: University Medical Center Groningen

\section{Acknowledgements}

We would like to express our appreciation to Dr. Henk Groen from the Department of Epidemiology, University Medical Center Groningen for his assistance on the cost calculations performed in this study.

\section{Funding}

This study was funded by the Netherlands Organisation for Health Research and Development (ZonMw). Ref: 80-82800-98-104.

\section{Availability of data and materials}

First author (M.L.) has unrestricted and unlimited access to the data and material.

\section{Authors' contributions}

All authors conceived the study and designed the trial. GJL, PCAJV, and EB obtained research funding. All authors supervised the conduct of the trial and data collection. ML, GJL, and PV undertook recruitment of participating centers and patients and managed the data, including quality control. ML and DJZ provided statistical advice on study design and analyzed the data. EB chaired the data oversight committee. ML drafted the manuscript, and all authors contributed substantially to its revision. EB takes responsibility for the paper as a whole. All authors have read and approved the final manuscript.

\section{Competing interests}

The authors declare that they have no competing interests.

\section{Consent for publication}

Not applicable.

\section{Ethics approval and consent to participate}

The study was obtained by from the University Medical Center Groningen Ethical Review Committee. Written informed consent was obtained from all participants

\footnotetext{
Author details

${ }^{1}$ Health Technology Assessment, Department of Epidemiology, University of Groningen, University Medical Centre Groningen, Hanzeplein 1, P.O. Box 30001, 9700 RB Groningen, The Netherlands. ²Department of Operations, Faculty of Economics \& Business, University of Groningen, Groningen, The Netherlands. ${ }^{3}$ Department of Neurology, University of Groningen, University Medical Centre Groningen, Groningen, The Netherlands.
}

Received: 8 August 2016 Accepted: 7 December 2016 Published online: 10 January 2017

\section{References}

1. Lahr MM, Luijckx GJ, Vroomen PC, van der Zee DJ, Buskens E. Proportion of patients treated with thrombolysis in a centralised versus a decentralised acute stroke care setting. Stroke. 2012:43:1336-40.

2. Hunter RM, Davie C, Rudd A, Thompson A, Walker H, Thomson N, et al. Impact on clinical and cost outcomes of a centralised approach to acute stroke care in London: a comparative effectiveness before and after model. PLoS One. 2013;8:e70420.

3. Meretoja A, Roine RO, Kaste $M$, Linna M, Roine $S$, Juntunen $M$, et al. Effectiveness of primary and comprehensive stroke centres: PERFECT stroke: a nationwide observational study from Finland. Stroke. 2010;41:1102-7.

4. Guzauskas GF, Boudreau DM, Villa KF, Levine SR, Veenstra DL. The costeffectiveness of primary stroke centres for acute stroke care. Stroke. 2012;43:1617-23.

5. Dirks M, Baeten SA, Dippel DW, van Exel NJ, van Wijngaarden JD, Huijsman $\mathrm{R}$, et al. Real-life costs and effects of an implementation program to increase thrombolysis in stroke. Neurology. 2012;79:508-14.

6. Verweij A, Sanderse C, Beer de J. Zijn er in nederland verschillen naar regio? in: Volksgezondheid toekomst verkenning, nationaal kompas volksgezondheid. bilthoven: RIVM. 2011. Available at: http://www. nationaalkompas.nl>. nationaal kompas Volksgezondheid \Bevolking. Accessed 8 Aug 2016

7. Gumbinger C, Reuter B, Stock C, Sauer T, Wiethölter H, Bruder I, et al. Time to treatment with recombinant tissue plasminogen activator and outcome of stroke in clinical practice: retrospective analysis of hospital quality assurance data with comparison with results from randomised clinical trials. BMJ. 2014;348:93429

8. Wahlgren N, Ahmed N, Dávalos A, Ford GA, Grond M, Hacke W, et al. Thrombolysis with alteplase for acute ischaemic stroke in the safe implementation of thrombolysis in stroke-monitoring study (SITS-MOST): An observational study. Lancet. 2007;369:275-82.

9. Ambulancezorg Nederland. Landelijke standaard meldkamer ambulancezorg (LSMA-2). 2011. Accessed 8 Aug 2016

10. Aries $\mathrm{E}$, Bosker $\mathrm{H}$, van Boven J, et al. Landelijk protocol ambulancezorg. herziene versie 7.2. 2011. Accessed 8 Aug 2016.

11. Plant Simulation. Siemens PLM. 2012. Available at: http://www.plm. automation.siemens.com/en_us/products/tecnomatix/plant_design/plant_ simulation.shtml. Accessed 8 Aug 2016.

12. Lahr MM, van der Zee DJ, Luijckx GJ, Vroomen PC, Buskens E. A simulation based approach for improving utilisation of thrombolysisin acute brain infarction. Med Care. 2013;51:1101-5.

13. Law AM, Kelton WD. Simulation modelling and analysis. 4th ed. New York: McGraw-Hill; 2007.

14. Law AM. ExpertFit Version 8 User's Guide. Tuscon: Averill M. Law \& Associates; 2011

15. The Dutch Healthcare Authority [Dutch]. 2010. Available at: https://www.nza nl/regelgeving/beleidsregels/. Accessed 8 Aug 2016.

16. European Central Bank. 2013. Available at: https://www.ecb.europa.eu/stats/ exchange/eurofxref/html/eurofxref-graph-usd.en.html. Accessed 8 Aug 2016.

17. Nallamothu BK, Bates ER, Wang Y, Bradley EH, Krumholz HM. Driving times and distances to hospitals with percutaneous coronary intervention in the United States: implications for prehospital triage of patients with ST-elevation myocardial infarction. Circulation. 2006:113:1189-95.

18. Nedeltchev K, Arnold M, Brekenfeld C, Isenegger J, Remonda L, Schroth G, et al. Pre- and in-hospital delays from stroke onset to intra-arterial thrombolysis. Stroke. 2003;34:1230-4.

19. Meretoja A, Keshtkaran M, Saver JL, Tatlisumak T, Parsons MW, Kaste M, et al. Stroke thrombolysis: save a minute, save a day. Stroke. 2014;45:1053-8.

20. Lees KR, Bluhmki E, von Kummer R, Brott TG, Toni D, Grotta JC, et al. Time to treatment with intravenous alteplase and outcome in stroke: an updated pooled analysis of ECASS, ATLANTIS, NINDS, and EPITHET trials. Lancet. 2010:375:1695-703

21. Fonarow GC, Smith EE, Saver JL, Reeves MJ, Bhatt DL, Grau-Sepulveda MV, et al. Timeliness of tissue-type plasminogen activator therapy in acute ischaemic stroke: patient characteristics, hospital factors, and outcomes associated with door-to-needle times within 60 minutes. Circulation 2011:123:750-8.

22. Hacke W, Donnan G, Fieschi C, Kaste M, von Kummer R, Broderick JP, et al ATLANTIS Trials Investigators; ECASS Trials Investigators; NINDS rt-PA Study Group Investigators. Association of outcome with early stroke treatment: pooled analysis of ATLANTIS, ECASS, and NINDS rt-PA stroke trials. Lancet. 2004;363:768-74. 
23. Rankin J. Cerebral vascular accidents in patients over the age of 60. II. Prognosis. Scott Med J. 1957;2:200-15.

24. Drummond M, Sculpher MJ, Torrance GW, Stoddart GL, O'Brien GJ. Methods for the economical evaluation of health care programs. 3rd ed. New York: Oxford University Press; 2005.

25. Tan SS, Bouwmans CA, Rutten FF, Hakkaart-van Roijen L. Update of the dutch manual for costing in economic evaluations. Int J Technol Assess Health Care. 2012;28:152-8.

26. Demaerschalk BM, Yip TR. Economic benefit of increasing utilisation of intravenous tissue plasminogen activator for acute ischaemic stroke in the United States. Stroke. 2005;36:2500-3.

27. Meretoja A, Strbian D, Mustanoja S, Tatlisumak T, Lindsberg PJ, Kaste M. Reducing in-hospital delay to 20 minutes in stroke thrombolysis. Neurology. 2012;79:306-13.

28. Meretoja A, Weir L, Ugalde M, Yassi N, Yan B, Hand P, Truesdale M, Davis SM, Campbell BC. Helsinki model cut stroke thrombolysis delays to 25 minutes in Melbourne in only 4 months. Neurology. 2013;81(12):1071-6.

29. Branas CC, MacKenzie EJ, Williams JC, Schwab CW, Teter HM, Flanigan MC, et al. Access to trauma centres in the United States. JAMA. 2005;293:2626-33,

30. Morris S, Hunter RM, Ramsay Al, Boaden R, McKevitt C, Perry C, et al. Impact of centralising acute stroke services in English metropolitan areas on mortality and length of hospital stay: difference-in-differences analysis. BMJ. 2014;349:94757.

31. van Zorgverzekeraars C. Handleiding voor kostenonderzoek [Dutch]. 2015. Available at: www.cvz.nl. Accessed 8 Aug 2016.

32. Claes N, Moeremans $K$, Frank B, Jef A, Jos V, Herman VL, et al. Estimating the cost-effectiveness of quality-improving interventions in oral anticoagulation management within general practice. Value Health. 2006;9:369-76.

33. Alberts MJ, Latchaw RE, Jagoda A, Wechsler LR, Crocco T, George MG, et al. Revised and updated recommendations for the establishment of primary stroke centres: a summary statement from the brain attack coalition. Stroke. 2011;42:2651-65.

\section{Submit your next manuscript to BioMed Central and we will help you at every step:}

- We accept pre-submission inquiries

- Our selector tool helps you to find the most relevant journal

- We provide round the clock customer support

- Convenient online submission

- Thorough peer review

- Inclusion in PubMed and all major indexing services

- Maximum visibility for your research

Submit your manuscript at www.biomedcentral.com/submit

) Biomed Central 